\title{
NO MONEY TO SPEND
}

Noвody can say that Mr. Johnson's budget for the coming fiscal year is calculated to win friends among scientists in the United States. It is much more likely to increase the irritation of those who have been saying, for several months now, that too much of the federal government's support for scientific activities of one kind or another is being spent on the attainmentand even, occasionally, the failure to attain-short term objectives. Congress is accustomed to deal more harshly with civil than with military projects in research and development. The Department of Defense can usually get a fair wind for the development of a new missile, but the Mohole project can be cancelled after a few desultory committee meetings. (Whatever the faults of Mohole may have been, it should now be clear that Congress would have been wiser to find some other way of saving money than to assume direct control of the affairs of what should be an independent agency.) Then there are the figures which show that expenditure on research and development in the United States has now decisively levelled. off. Between 1967 and 1968, the budget estimates for military research and development amount to an increase of 7.2 per cent, but the amount to be spent on civil activities (including space flight) will be almost unchanged. In the circumstances it is no wonder that the physicists have taken a somewhat masochistic pleasure in pointing out (Physics Today, 20, 99; 1967) that the trend of expenditure on research in physics now lags a long way behind the target the physicists were encouraged to design for themselves only a year ago.

But what is to be done? There are two issues to be decided-the level of expenditure on research and development appropriate to an advanced society like that in the United States, and the proportion of this that should be spent on basic research. So far there are only rules of thumb and the dictates of arbitrary shifts of public policy to decide how much to spend and where. Even expenditure on military research and development is not as direct a consequence of what the military planners consider to be military necessity as they would like to think. A great many projects, for example, cannot be attempted for lack of men. For the research and development budget as a whole, men and their availability are also crucial. The host of decisions which go to make up a complete budget of the kind now published in the United States is tanta. mount to a decision about what proportion of the country's skilled manpower can be devoted to creative research and development. In the circumstances, it is meaningful to protest that the administration may have made wrong choices about the allocation of its resources. In the United States, it is remarkable how many of the projects now being undertaken in the belief that they will bring industrial advancement of some kind or another are being financed from federal money.
Why cannot industrialists make their own decisions in these matters? On basic research, the best eriterion so far for deciding how much should be spent is that there should be enough to keep educators enlivened and their students provided with problems on which to cut their teeth. One of the cogent objections to the present arrangements for financing basic civil research in the United States is that a large proportion of the money available comes from what are called missionoriented agencies. In the nature of things, these are not equipped to make disinterested decisions about the pattern of work and education in universities and similar establishments. It could not fail to be a benefit if some of their largesse were channelled through institutions like the National Science Foundation more able to keep closely in touch with what is happening in the laboratories. That way, there might beless complaint and, more important, some hope of constructing the volume of case-law necessary if objective yardsticksabout the pattern of spending are eventually to be designed.

\section{CLOSING THE STABLE DOOR}

THE statement on information exchange groups by the Commission of Biological Editors which appears on page 547 is reasonable and predictable, if a little late in the day. It amounts to a declaration of contrary interest by an influential group of biological journals. If the IEG scheme had still been in full flood, this statement would have given the organizers and the members cause to reconsider what they were about. In the event, the National Institutes of Health have had the good sense to sce that the experiment could not flourish without creating contradiction, and the groups are to be discontinued. That is a welcome development, but it does not follow that the statement is redundant. The horse may never have the strength to bolt, but it is only sensible to shut the stable door. The statement will put clearly on record the case for hoping that other experiments similar to IEG will not in future be attempted. It will also draw attention to the need for channels of communication in science with those attributes which made the IEG experiment attractive. Because the IEG seem to be coming to an end, there is no case for treating the long-term questions less urgently.

The case against IEG is now familiar, and needs no rehearsal. The biological editors are wise, however, to work from the assumption that the activities of the exchange groups were indistinguishable from publication in the more orthodox sense. There is no point in beating about that bush. Publication is broadcast writing, and the circulation of preprints to the large and often anonymous membership of some of the exchange 